\title{
DESTILAÇÃO DE SOLUÇÕES ETANÓLICAS SALINAS
}

\author{
R. D. PEREIRA ${ }^{1}$, A. BERNARDO ${ }^{1}$, L. F. MOURA ${ }^{1}$ e M. GIULIETTI ${ }^{1}$ \\ ${ }^{1}$ Universidade Federal de São Carlos, Departamento de Engenharia Química \\ E-mail para contato: rauberdp@gmail.com
}

\begin{abstract}
RESUMO: O trabalho teve por objetivo o estudo da adição de sais em misturas de etanol e água, a fim de se obter uma rota alternativa à produção do etanol anidro. $\mathrm{O}$ estudo foi conduzido a partir de ensaios em laboratório para obtenção de parâmetros de interação binária entre os componentes em mistura, que foram utilizados no modelo de obtenção do coeficiente de atividade NRTL-Electrolyte. Esse modelo por sua vez, foi utilizado para estimativa e previsão do comportamento do equilíbrio líquido-vapor da mistura. Os dados experimentais referentes ao equilíbrio líquido vapor da mistura ternária água/etanol/sais foram comparados com dados da literatura e com a previsão do modelo NRTLElectrolyte. Concluiu-se que há o deslocamento do ponto de azeotropia da mistura, como esperado, e que o modelo NRTL-Electrolyte apresentou satisfatória previsão do comportamento da mistura, o que viabiliza estudos em maior escala da estratégia de purificação apresentada no presente trabalho.
\end{abstract}

\section{INTRODUÇÃO}

Os processos de obtenção do etanol são utilizados amplamente em escala industrial, devido à grande importância do etanol em processos da indústria alcoolquímica (que utilizam o etanol como matéria-prima), na utilização do mesmo como combustível, e em vários outros processos onde o etanol pode ser utilizado para purificação de produtos e extração de substâncias em determinados processos. O etanol é obtido de maneira convencional na condição de etanol hidratado, com cerca de $92 \%$ de etanol em massa, devido à presença de azeotropia da mistura etanol/água. Porém, diversas estratégias de purificação do etanol para o grau de anidro $(99,3 \% \mathrm{~m} / \mathrm{m})$ foram desenvolvidas a fim de suprir as demandas desse produto nas diversas aplicações citadas acima.

Técnicas de purificação que têm por objetivo alterar o ponto de azeotropia, ou até mesmo o suprimir, têm sido desenvolvidas com o passar do tempo, dentre elas a adição de solventes, a utilização de peneiras moleculares que têm seu comportamento regido pelo fenômeno de adsorção, e a adição de sais e substâncias orgânicas na mistura etanólica, como fonte de estudo para a viabilização de sua utilização em escala de produção industrial. Porém, apesar da grande importância e utilização do etanol, a determinação do comportamento termodinâmico da solução torna-se uma dificuldade, uma vez que a mistura apresenta não idealidade intrínseca. Faz-se necessário a utilização de modelos termodinâmicos mais complexos, que levam em consideração a interação de todos os componentes da mistura, inclusive solvente/sais. A interação entre as espécies em solução é dada a partir de parâmetros que podem ou não ser dependentes da temperatura. Tornam-se então necessários ensaios laboratoriais para a obtenção de dados experimentais como composição e temperatura de 
destilado, com o objetivo de se determinar os parâmetros de interação que serão utilizados no modelo de previsão dos coeficientes de atividade da mistura. O modelo em estudo, NRTLElectrolyte fornece uma boa aproximação do comportamento assumido por diversas soluções no equilíbrio líquido-vapor, e por isso tornou-se objeto de estudo no presente trabalho.

A importância do estabelecimento de modelos mais adequados, mesmo que aproximados para soluções etanólicas iônicas e não-iônicas adquire dimensões importantes no campo da Engenharia Química, pois sua utilização pode ser difundida rapidamente pela disponibilidade do etanol e pelo seu baixo custo, fatores cruciais no desenvolvimento da tecnologia de purificação do etanol. Vários dos processos atualmente utilizados para obtenção do etanol anidro apresentam alto investimento inicial e gastos com manutenção, como as zeólitas utilizadas no processo de adsorção de água do etanol, o que motiva o desenvolvimento de processos mais acessíveis econômica e operacionalmente, como é o caso da adição de sais na mistura etanólica.

\section{MATERIAIS E MÉTODOS}

Buscou-se inicialmente o desenvolvimento de um aparato experimental que possibilitasse a obtenção de dados de equilíbrio líquido vapor de maneira satisfatória. O equipamento desenvolvido conforme mostra a Figura 1, consiste no balão volumétrico contendo a mistura a ser aquecida até o ponto de bolha, seguido por uma conexão contendo um "poço" com válvula para coleta do condensado, e o condensador tipo serpentina que impede qualquer perda de vapor para o ambiente.

Figura 1 - Aparato experimental utilizado.

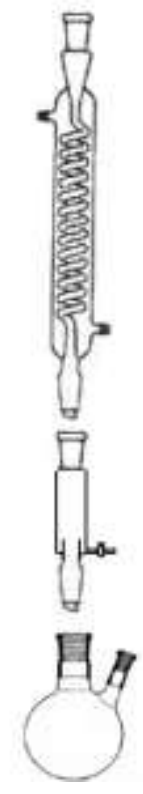

A princípio, antes dos ensaios serem iniciados com a mistura ternária (água, etanol e sal), utilizou-se o equipamento para soluções hidro alcóolicas apenas, uma vez que se desejou comparar os dados obtidos experimentalmente para diferentes pontos do equilíbrio líquidovapor da mistura com os dados já consolidados na literatura para o mesmo sistema. Outro 
ponto importante estudado foi o tempo de coleta da amostra de condensado. Após o líquido entrar em ebulição, o condensado passava a se acumular no poço da conexão acima do balão, até o início do "transbordamento" da solução condensada de volta para o balão. Nesse ponto, coletaram-se amostras do balão volumétrico e do condensado, que representaram a fase líquida e a fase vapor do equilíbrio, respectivamente. Dessa forma, se estabeleceu ensaios com diferentes tempos de coleta do condensado para definição do tempo que melhor representava a composição de vapor no equilíbrio líquido-vapor.

As composições em etanol das amostras foram analisadas com o auxílio de um refratômetro portátil Mettler Toledo, e construiu-se uma curva de calibração para o índice de refração, como pode ser observado na Figura 2. A curva de calibração do índice de refração em função da composição em etanol tem comportamento linear na faixa de 0 a $25 \%$ de etanol em base mássica. Assim, todas as diluições foram realizadas para que suas composições ficassem dentro da faixa da curva de calibração.

Figura 2 - Curva de calibração.

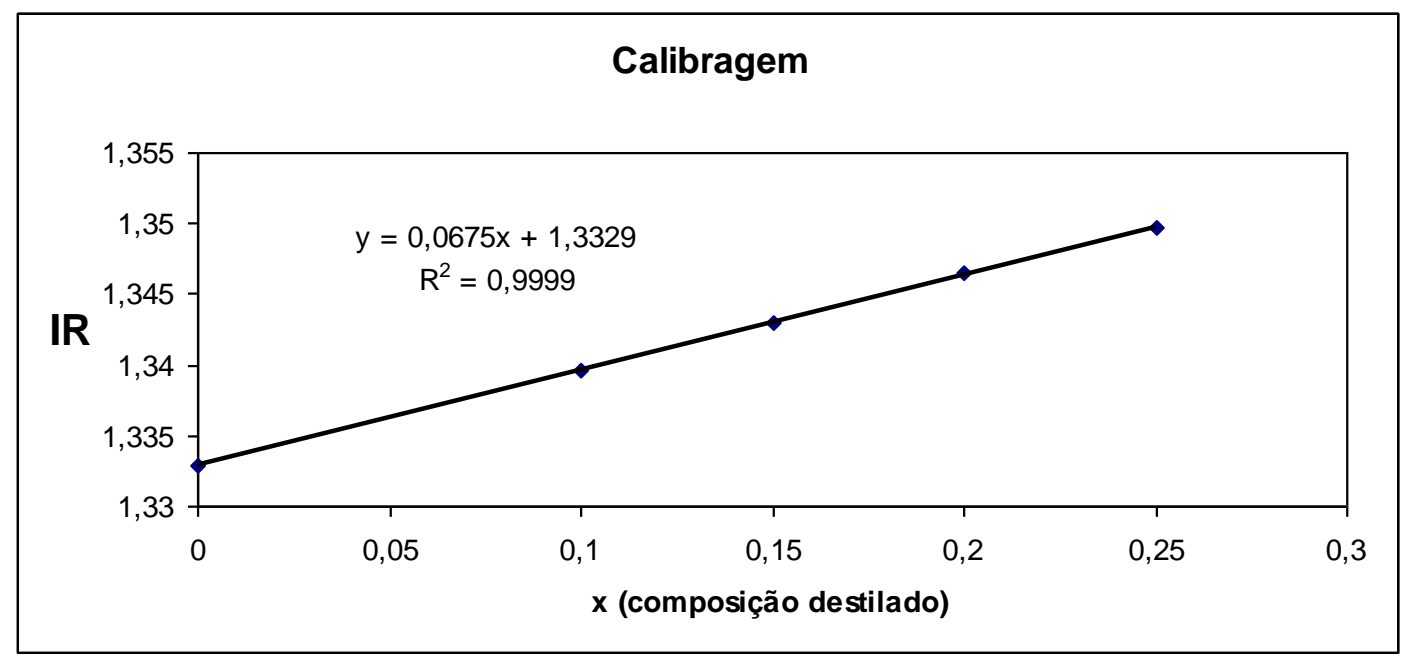

Após determinada a confiabilidade do aparato experimental desenvolvido, e antes de iniciar os testes com o sistema ternário (etanol, água e sal), escolheu-se o cloreto de cálcio $(\mathrm{CaCl} 2)$ como o sal a ser misturado nas soluções hidro alcóolicas, devido ao seu elevado efeito de "salting out" em solução, fato esse que levou diversos trabalhos, dentre eles, Nishi (1975) a utilizar o sistema etanol/água/CaCl2 para obtenção de dados de equilíbrio líquidovapor experimentalmente. Llano-Restrepo e Aguilar-Arias (2002) utilizaram o modelo NRTL-Electrolyte para o sistema etanol/água/CaCl2 e compararam os dados de composição de etanol no vapor calculados, com os dados apresentados em Nishi (1975) para o mesmo sistema.

Para o presente trabalho, desenvolveu-se o modelo NRTL-Electrolyte em linguagem VBA para a simulação do equilíbrio do sistema etanol/água/CaCl2. Para o equilíbrio líquidovapor em questão, utilizou-se a equação de Raoult Modificada, que é mostrada na Equação1. Houve a necessidade de testar a linha de código do modelo. Para tanto, iniciou-se a simulação utilizando como variáveis, os parâmetros de interação entre o sal CaCl2 e etanol, uma vez que os parâmetros de interação entre o sal e a água estão presentes na literatura. Como função 
objetivo utilizou-se a minimização das diferenças dos quadrados da composição de vapor e temperatura entre os dados calculados e aqueles presentes em Nishi (1975).

$$
y_{i}, P=\gamma_{i}, x_{i}, P_{i}^{\text {sat }}
$$

Iniciaram-se então os ensaios laboratoriais com as misturas contendo etanol, água e $\mathrm{CaCl} 2$, mantendo a concentração em massa desse último em 16,7\% com base livre de sal. As amostras iniciais foram preparadas de forma a reproduzir as composições iniciais utilizadas por Nishi (1975), e o condensado por sua vez foi coletado a partir da válvula presente no "poço" do equipamento conectado acima do balão volumétrico, como mostrado na Figura 1.

Os pontos experimentais de equilíbrio líquido-vapor do ternário foram utilizados para novamente estimar os parâmetros de interação binária entre o sal e o etanol, necessários para a previsão do coeficiente de atividade pelo modelo NRTL-Electrolyte.

\section{RESULTADOS E DISCUSSÃO}

Os ensaios experimentais utilizando apenas etanol e água foram conduzidos no aparato experimental da Figura 1. Inicialmente o tempo de espera para a coleta do destilado, após o início da condensação no poço de coleta, foi variado entre 5, 20, 30, 60 e 120 minutos, para a mesma composição inicial de etanol no balão, de $38 \%$ em massa. A variação dos tempos foi necessária para determinar o tempo em que o sistema entra em equilíbrio. Os valores dos desvios para cada tempo de espera entre a composição do vapor experimental e da literatura são apresentados na Tabela 1.

Tabela 1 - Resultados obtidos de composição do condensado para diferentes tempos de coleta

\begin{tabular}{|c|c|c|c|}
\hline Tempo (min) & y experimental & y teórico & Desvio (\%) \\
\hline 5 & 0,78 & 0,75 & 4,53 \\
\hline 5 & 0,79 & 0,75 & 5,36 \\
\hline 5 & 0,77 & 0,75 & 3,67 \\
\hline 20 & 0,78 & 0,75 & 3,77 \\
\hline 20 & 0,77 & 0,75 & 3,38 \\
\hline 20 & 0,77 & 0,75 & 2,89 \\
\hline 30 & 0,80 & 0,75 & 6,21 \\
\hline 60 & 0,81 & 0,75 & 8,01 \\
\hline 120 & 0,83 & 0,75 & 10,03 \\
\hline
\end{tabular}

Observou-se que para maiores tempos de espera, o valor do desvio aumentava, consequência do problema de homogeneização da amostra de condensado no "poço" próximo à válvula de coleta, uma vez que o mesmo possui cerca de $2,0 \mathrm{~cm}$ de profundidade, o que dificultou a homogeneização da solução que se encontrava no topo e no fundo do mesmo. Mediante tal conclusão, estabeleceu-se que o tempo necessário para coleta da amostra deveria se dar no momento que o poço estivesse com amostra de condensado suficiente para fazer a análise do refratômetro, diminuindo o tempo de espera para coleta em apenas alguns segundos. 
Os ensaios com a adição de sal na solução hidro alcóolica foram realizados e assim, estimados os parâmetros de interação binária, que diferiram daqueles obtidos por Nishi (1975). Os parâmetros obtidos pelos dados experimentais levantados são mostrados na Tabela 2. Os índices " 1 " e "3" indicam as substâncias referentes ao parâmetro de interação binária, sendo etanol e $\mathrm{CaCl} 2$ respectivamente.

Tabela 2 - Constantes estimadas utilizadas no modelo NRTL-Electrolyte

\begin{tabular}{|c|c|}
\hline Constantes & Valores \\
\hline$\alpha 13$ & 0,039 \\
\hline$\tau 13$ & 38,184 \\
\hline$\tau 31$ & $-18,807$ \\
\hline
\end{tabular}

Os experimentos foram conduzidos com concentração de sal constante e igual a 16,7\% em massa (em base livre de sal) para as diferentes concentrações iniciais de etanol em solução, que variou de 2 a $80 \%$ em base molar, com o objetivo de repetir os pontos utilizados por Nishi (1975), a caráter de comparação. Os valores de concentração de etanol no destilado e de temperatura para cada ensaio foram comparados com os obtidos na literatura.

Foi possível assim, comparar os dados da literatura de equilíbrio líquido-vapor para o sistema ternário com os obtidos experimentalmente e com a simulação utilizando o modelo NRTL-Electrolyte para previsão do coeficiente de atividade utilizado na equação de Raoult Modificada. A Figura 2 mostra o gráfico gerado, comparando os diferentes dados utilizados.

Observou-se que o azeótropo foi deslocado ou até mesmo eliminado no sistema ternário, uma vez que quando analisados os valores de composição de etanol no vapor do sistema salino percebeu-se a quebra da azeotropia. Por volta do teor de $80 \%$ molar de etanol, as curvas do sistema contando sal não coincidiram com a diagonal, diferente da curva binária etanol/água, o que comprovou a quebra de azeótropo para o sistema.

Os desvios entre os valores obtidos por Nishi (1975) e os experimentais levantados no presente trabalho se devem a dois fatos. O primeiro fundamenta-se de que o sal utilizado no experimento não estava livre de água, uma vez que $\mathrm{CaCl} 2$ é higroscópico. O "salting out" promovido pelo sal depende da quantidade de água presente no mesmo antes de estar em solução com etanol e água. Sendo assim, não foi possível determinar que os teores de água no sal utilizados no presente trabalho foram os mesmos do utilizado no trabalho de Nishi (1975). Outro fato que pode justificar o desvio entre os valores de teor de etanol no vapor foi de que as pressões atmosféricas dos dois ensaios diferiram entre si. Quanto maior a pressão atmosférica, menor será a volatilidade de etanol, o que acarreta em um deslocamento da curva de equilíbrio para baixo. 
Figura 3 - Gráfico de ELV para Etanol da solução Etanol/Água/CaCl2.

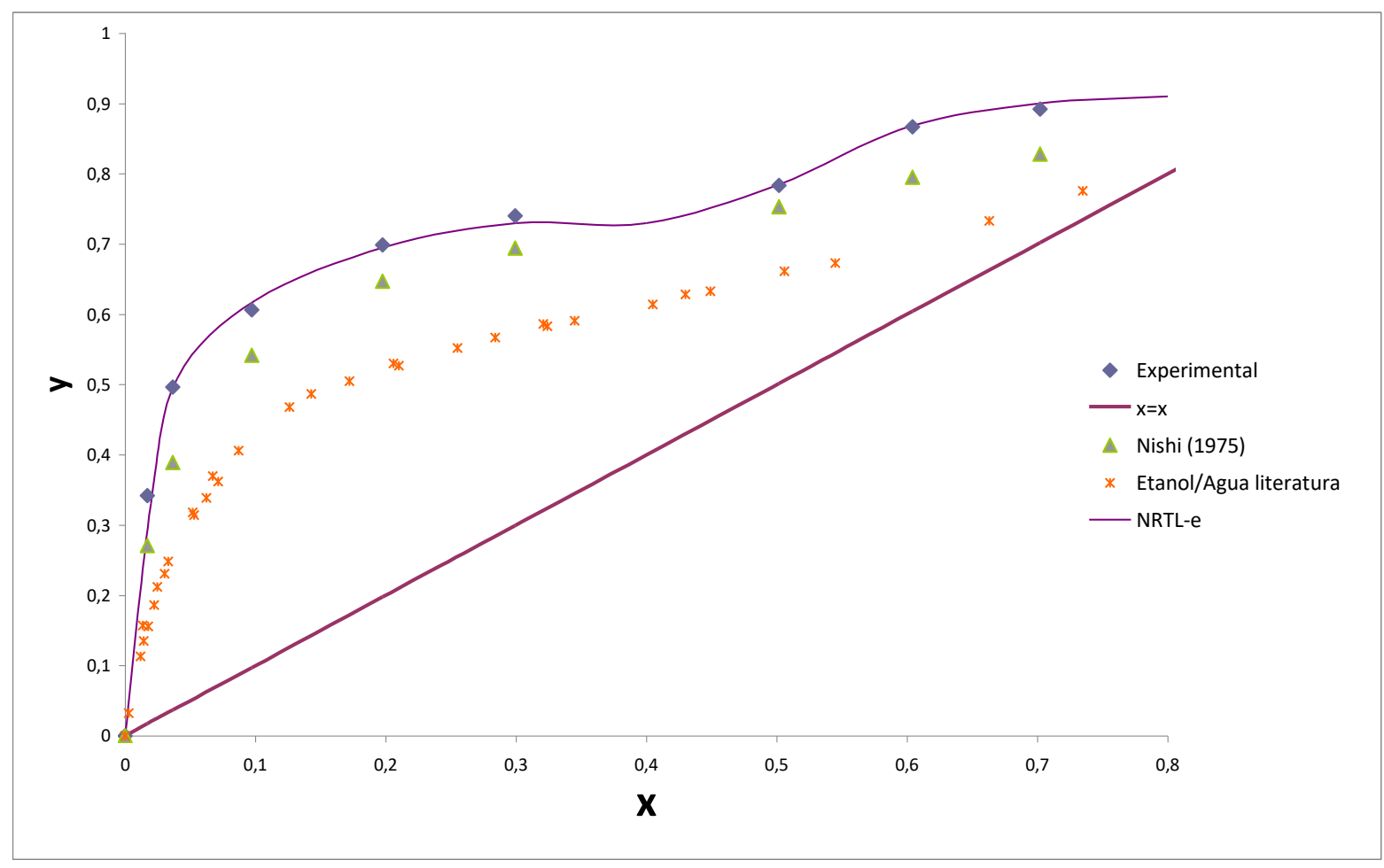

\section{CONCLUSÕES}

Os experimentos de equilíbrio líquido vapor foram conduzidos de forma satisfatória e foi possível a obtenção de dados coerentes com os presentes na literatura. Diferenças entre os valores experimentais e de simulação realizados com aqueles apresentados por outros autores, devem-se principalmente por diferenças de metodologia de realização do experimento, bem como diferenças no método de análise. Vale ressaltar que não se tem exatidão na comparação entre os sais utilizados no experimento e por Nishi(1975), o que explicaria os desvios apresentados, uma vez que o sal é fator de ação direta no deslocamento ou até extinção do ponto de azeotropia na destilação etanol/água. O modelo NRTL-Electrolyte utilizado nas simulações mostrou-se coerente com os valores experimentais e com os obtidos em simulações anteriores por outros autores.

\section{REFERÊNCIAS}

LLANO-RESTREPO, M.; AGUILAR-ARIAS, J. Modeling and simulation of saline extractive distillation columns for the production of absolute ethanol. School of Chemical Engineering, Universidad del Valle, Apartado 25360, Cali, Colômbia, 2002.

NISHI, Y. Vapor-liquid equilibrium relations for the system accompanied by hypothetical chemical reaction containing salt. Faculty of Engineering, Ehime University, Matsuyama, 790, 1975. 